\title{
Zygomatic Buttress
}

National Cancer Institute

\section{Source}

National Cancer Institute. Zygomatic Buttress. NCI Thesaurus. Code C94592.

The portion of the maxillary jaw bone and other facial bones that form the most lateral mid face skeletal structure known as the cheekbone. 